\title{
Is it possible to eliminate the number of inappropriate thyroid surgeries combining scintigraphy and cytology?
}

Smaroula Divani $^{*}$, George Kalodimos ${ }^{2}$, Pavlos Skoufogiannis ${ }^{2}$, George Kitsakis ${ }^{2}$, Angela Fericean ${ }^{2}$ Athanassia Bamiha $^{3}$.

${ }^{1}$ Department of Clinical Cytology, General Hospital of Volos, Volos, Magnesia-Thessaly, Greece

${ }^{2}$ Pathology Department, General Hospital of Volos, Volos, Magnesia-Thessaly, Greece

${ }^{3}$ Department of Surgery, General Hospital of Volos, Volos, Magnesia-Thessaly, Greece

*Corresponding Author: Smaroula Divani, Department of Clinical Cytology, General Hospital of Volos, Volos, Magnesia-Thessaly, Greece Received date: March 02, 2020; Accepted date: April 10, 2021; Published date: May 07, 2021

Citation: Divani S., Kalodimos G, Skoufogiannis P., Kitsakis G., Fericean A., Bamiha A. (2021) Is it possible to eliminate the number of inappropriate thyroid surgeries combining scintigraphy and cytology? Clinical Medical Reviews and Reports. 3(5); DOI:10.31579/2690-8794/076

Copyright: @2021, Divani S., This is an open access article distributed under the Creative Commons Attribution License, which permits unrestricted use, distribution, and reproduction in any medium, provided the original work is properly cited.

\section{Abstract \\ Objective: Although fine needle aspiration cytology (FNAC) is the most reliable, safe and accurate method for the clinical management of abnormal thyroid nodules, $5 \%-15 \%$ of cases lead to indeterminate diagnoses and surgery is the recommended practice for them as they may be malignant. Nevertheless, the majority of cases with indeterminate cytology are benign, so the risk of unnecessary surgery is significant. In our study we combined FNAC and scintigraphy in order to reduce the number of inappropriate surgeries.}

Subjects and Methods: From 219 patients with thyroid fine needle aspiration cytology 33(9 males and 24 females) aged 18-73 years, had indeterminate FNAC diagnoses and were referred for scintigraphy. Surgery was performed in all cases. The results of FNAC, scintigraphy and histology were collected and compared.

Results: From 33 cases with indeterminate cytology 32 had a benign histological diagnosis and only one was malignant (follicular Ca). That case had a positive scan. All cases with negative thyroid scans (29/33) were benign. False positive scans were 3 , whereas one scan was true positive with final diagnosis follicular carcinoma.

Conclusion: This study showed that combining the FNAC with the thyroid scintigraphy in cases of thyroid nodules with indeterminate cytology it is possible to reduce the number of inappropriate surgeries from 32 to 3.

Keywords: thyroid gland, fine needle aspiration, scintigraphy, thyroid surgery

\section{Introduction}

Although thyroid nodules are not a rare problem and it is well known that most of them are a result of a benign disease process, it is clinically important to exclude malignancy.

Thyroid nodules are usually asymptomatic and found on physical examination or incidentally with the use of sensitive imaging techniques. Nodules of various sizes are being detected in up to $65 \%$ of the general population (more frequent in women) but only about $4 \%-6,5 \%$ of all thyroid nodules are found to be malignant [1].

The techniques used to detect malignant cases include ultrasonography, thyroid scintigraphy, serum markers, fine needle aspiration cytology as well as molecular biomarkers that can be powerful adjunct to cytology.

Thyroid fine needle aspiration cytology (FNAC) is the most reliable, safe and accurate method particularly under ultrasound guidance (US FNAC) in order to decrease the rate of false negative or non-diagnostic cases [1, 2]. However the cytological findings from approximately $20 \%-30 \%$ of cases lead to indeterminate diagnoses and performing ultrasound guidance there is a 5\%-15\% risk of non diagnostic cytology [3-9].

Cases of follicular lesions cannot be accurately evaluated since it is not possible to exclude capsular or vascular invasion $[10,11]$. The vast majority of cases with indeterminate cytology are benign, so the risk of unnecessary surgery is significant [12-14]. Thyroid scintigraphy remains critical for the evaluation of autonomously functioning thyroid tissue [15].

In this study we combined FNAC and scintigraphy in order to have the right preoperative selection of patients and reduce the number of inappropriate surgeries.

\section{Subjects and Methods}

Thirty three patients that fell into an indeterminate category after FNAC, were selected for the current study. All were patients with single nodules more than $1 \mathrm{~cm}$ in size. The age of the patients ranged from 18 to 73 years with mean age 39 years. Twenty four patients were females and 9 were 
males (male to female ratio 3/8). The selected cases had recommendations for FNAC based on experts opinion, mainly suspicious sonographic and/or clinical features.

Before injection patient stayed at a quite environment. The thyroid scans were obtained after intravenous administration of $100 \mathrm{MBq}$ of technetium-

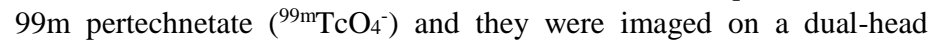
Siemens gamma camera (E- Cam, Siemens Electronics, Erlangen, Germany) 20 and 60 minutes later. All scans were obtained in the anterior position.

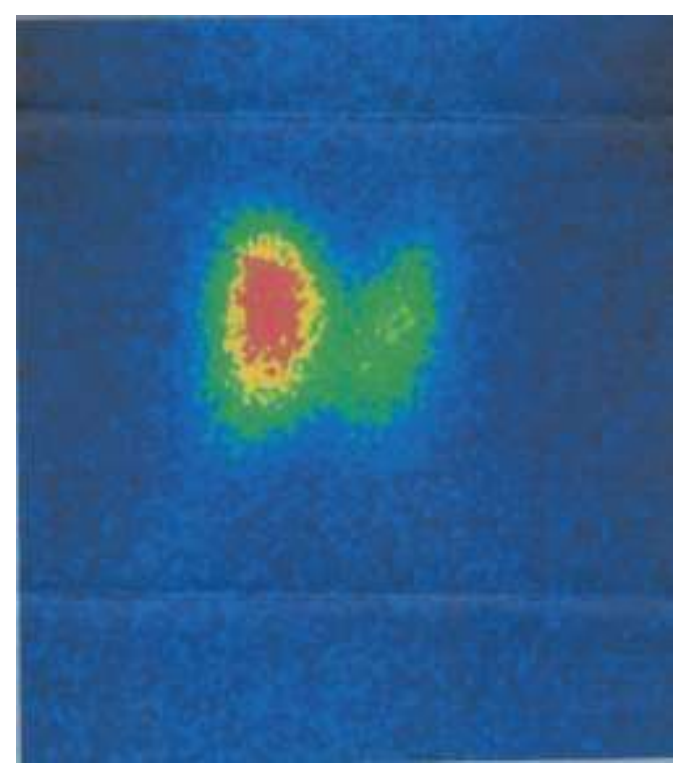

Final histological diagnoses were evaluated by three experienced pathologists after surgery in all 33 patients.

The results of FNAC, scintigraphy and histology were compared.

\section{Results}

From 32 cases with histologically benign diagnosis (Table 1), 29 cases had negative thyroid scans (Figure 1).

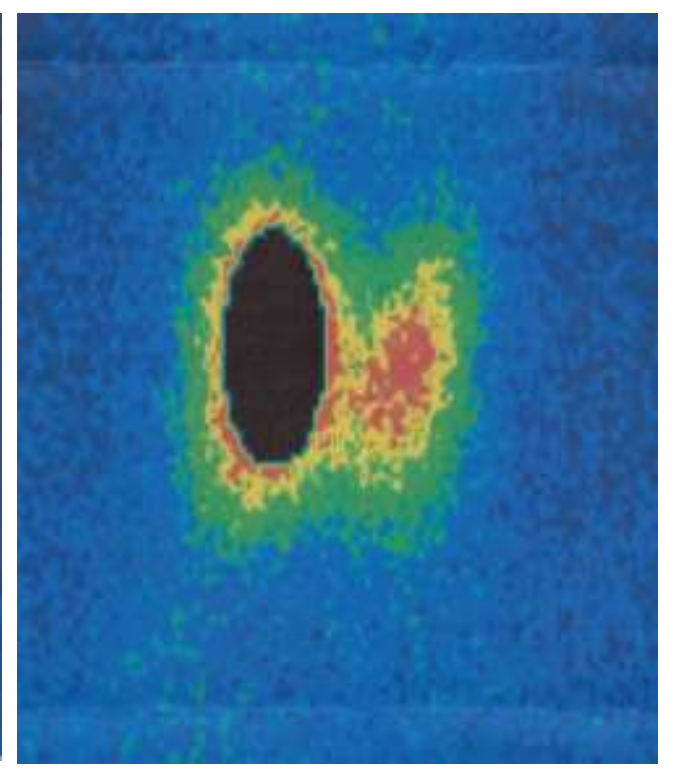

Figure 1. Thyroid scan.

\begin{tabular}{|l|c|c|}
\hline Histologic diagnosis & Benign & Malignant \\
\hline Papillary carcinoma & - & - \\
\hline Follicular carcinoma & - & 1 \\
\hline Follicular adenoma & 4 & - \\
\hline Hyperplastic goiter & 11 & - \\
\hline Colloid goiter & 17 & - \\
\hline
\end{tabular}

Table 1. Histologic results in cases with non-diagnostic cytology.

Three patients with follicular adenoma had false positive scans (false positive results by scintigraphy).

However all cases with negative thyroid scans (29/33) proved to be benign histologically (11 cases with hyperplastic goiter, 17 with colloid goiter and 1 with follicular adenoma).

The only one patient with follicular carcinoma (Figure 2) but nondiagnostic cytology had a positive scan.

Thirty two out of 33 cases that were not diagnostic cytologically had benign final histologic diagnoses, so the risk of missing carcinomas by FNAC proved to be very low $1 / 33$. Scintigraphy gave positive results in 4 cases 4/33 (1 true positive and 3 false positive.)

In conclusion, fine needle aspiration of the thyroid proved to be a reliable, inexpensive, sensitive and specific procedure for discriminating between surgical and non-surgical nodules [16-22]. It offers the best preoperative assessment of solitary thyroid nodules [23]. However diagnostic difficulties appear in many cases leading to 5\%-20\% non diagnostic cases. Follicular lesions including follicular-the most common-variant of papillary carcinoma, must be accurately diagnosed (gray zone).
For indeterminate cases surgery is still the current recommended practice, as they may harbor neoplastic potential $[24,25]$.

Immunocytochemistry and molecular testing are a powerful adjunct to cytology, incorporated in the algorithms of the American Thyroid Association guidelines [8] that are used to manage patients with indeterminate thyroid nodules.

In our study one out of thirty three cases with non diagnostic cytology revealed malignancy, whereas the remaining large majority of cases had benign final histological results, concerning mainly colloid goiter and hyperplastic goiter.

It is well known that the probability of thyroid malignancy is higher in hypofunctioning nodules and thyroid scintigraphy is the only test able to show the presence of autonomously functioning thyroid tissue.

The specificity of thyroid scan was found to be $20 \%-21,1 \%$ [26-28]. However the specificity is $88 \%$ in other studies [4]. Many researchers agree that thyroid scans are not sufficient to rule out surgery and cannot be used as a routine technique. 
In our study all patients with negative thyroid scans had benign histological diagnoses, on the contrary in the positive scans there were three false positive cases.

Combining the fine needle aspiration cytology with the thyroid scintigraphy in cases of thyroid nodules with indeterminate cytology, we have the opportunity to reduce the number of inappropriate surgeries [29].

Our results show that unnecessary surgery could have been reduced from 32 to 3 cases combining cytology and scintigraphy.

Since the majority of the patients with indeterminate cytology do not have cancer and scintigraphy can detect the benign cases, it seems advisable to perform thyroid scans in order to eliminate the number of inappropriate thyroid surgeries.

\section{Reference}

1. Chow LS GH, Goellner JR, van Heerden JA. (2001) Non diagnostic thyroid fine-needle aspiration cytology: management dilemmas. Thyroid. 11:1147-51.

2. Mc Henry CR, Walfish PG, Rosen IB. (1993) Non diagnostic fine needle aspiration biopsy: a dilemma in management of nodular thyroid diseases. Am Surg. 59(7): 415-9.

3. Dos Santos MT, Buzolin AL, Gama RR et al. (2018) Molecular classification of thyroid nodules with indeterminate cytology. Development and validation of a highly sensitive and specific new MiRNA-Based Classifier Test Using Fine Needle Aspiration Smear Slides. Thyroid. 28(12).

4. Luca Giovanella, Suriano S, Maffioli M, Luca C, Spriano G. (2010) ${ }^{99 M}$ Tc-SESTAMIBI Scanning in thyroid nodules with nondiagnostic cytology. Head and Neck. 32(5):607-611, doi:10.1002/hed.21229. Published on line.

5. Oriha IB, Hamrahian AH, Reddy SS. (2004) Management of nondiagnostic thyroid fine needle aspiration biopsy: survey of endocrinologists. Endocr Pract. 10: 317-24.

6. Alexander EK, Heering JP, Benson CB et al. (2002) Assessment of nondiagnostic ultrasound-guided fine needle aspiration of thyroid nodules. J Clin Endocrinol Metab. 87(11): 4924-7.

7. Gharib H, Papini E, Valcavi R et al. (2010) American Association of Clinical Endocrinologists and Assiciazione Medici Endocrinologi medical quidelines for clinical practice for the diagnosis and management of thyroid nodules. Endocr Pract. 16 (1): $1-43$.

8. Cooper DS, Doherty GM, Haugen BR et al. (2009) Revised American Thyroid Association management quidelines for patients with thyroid nodules and differentiated thyroid cancer. Thyroid. 19(11): 1167-214.

9. Hambleton C and Kandil E. (2013) Appropriate and accurate diagnosis of thyroid nodules: a review of thyroid fine needle aspiration. Intern J Clin Exper Med. 6 (6): 413-22.

10. Rosai J. (2005) Handling of thyroid follicular patterned lesions. Endocr Pathol. 6 (issue?): 279-83.

11. Shih SR, Shun CT, Su DH et al. (2005) Follicurar variant of papillary thyroid carcinoma. Diagnostic limitations of fine needle aspiration cytology. Acta Cytol. 49: 383-6.

12. Baloch ZW, Fleisher S, Li Volsi VA, Gupta PK. (2002) Diagnosis of follicular neoplasm: a gray zone in thyroid fine needle aspiration. Diagn Cytopathol. 26 (1): 41-4.

13. Lobo C, McQueen A, Beale T, Kocjan G. (2011) The UK Royal College of Pathologists. Thyroid fine needle aspiration diagnostic classification is a robust tool for the clinical management of abnormal thyroid nodules. Acta Cytol. 55(6): 499-506.
14. Kholova I, Ludvikova M. (2014) Thyroid atypia of undetermined significance or follicular lesion of undetermined significance: an indispensable Bethesda 2010 diagnostic category or waste garbage? Acta Cytol. 58 (4): 319-29.

15. Tanju T, Ozker, Kabasakal I, Kermaz B. (2000) The role of ${ }^{99 m}$ TcMIBI and TI 201 in diagnosis of thyroid cold nodules. Eur Nucl Med. 27: 713-20.

16. Bongiovanni M, Spitale A, Faquin WC et al. (2012) The Bethesda System for Reporting Thyroid Cytopathology: a meta analysis. Acta Cytol. 56(4): 333-9.

17. Cibas ES, Ali SZ. (2009) The Bethesda System for Reporting Thyroid Cytopathology. Thyroid. 19(11): 1159-65.

18. Kocjan G, Chandra A, Cross PA et al. (2011) The interobserver reproducibility of thyroid fine needle aspiration using the UK Royal College of Pathologists classification system. Amer J Clin Pathol. 135(6): 852-9.

19. Ardito G, Rossi ED, Revelli L et al. (2010) The role of fine needle aspiration performed with liquid based cytology in the surgical management of thyroid lesions. In Vivo. 24(3): 333-7.

20. Nggda H, Musa A, Gali B, Khalil M. (2006) Fine needle aspiration cytology of thyroid nodule:a Nigerian tertiary hospital experience. Internet Journal of Pathology. 5(1).

21. Agrawal S. (1995) Diagnostic accuracy and role of fine needle aspiration cytology in management of thyroid nodules. J Surg Oncol. 58(3):168-172.

22. Nasuti JF, Gupta PK, BalochWZ. (2002) Diagnostic value and cost-effectineness of on-site evaluation of fine needle aspiration specimens: review of 5,688 cases. Diagn Cytopathol. 27(1):1-4.

23. Tabaqchali MA, Hanson JM, Johonson SJ, Wadehra V, et al. (2000) Thyroid aspiration cytology in Newcastle: a six year cytology/histology correlation study. Annals of the Royal College of Surgeons of England. 82(3):149-155.

24. Cooper DS. (2009) Revised American Thyroid Association management guidelines for patients with thyroid nodules and differentiated thyroid cancer. Thyroid. 19(11):167-214.

25. Yeh MW, Demircan O, Ituarte P, et al. (2004) False negative fine needle aspiration cytology results delay treatment and adversely affect outcome in patients with thyroid carcinoma. Thyroid. 14(3):207-215.

26. Basharat R, Bukhari MH, Saeed S, Hamid T. (2011) Comparison of fine needle aspiration cytology and thyroid scan in solitary thyroid nodule. Pathol Res Int. 754041.

27. Lumachi F, Varotto L, Borsato S, et al. (2004) usefulness of ${ }^{99 \mathrm{~m}} \mathrm{Tc}$ pertechnetate scintigraphy and fine needle aspiration cytology in patients with solitary thyroid nodules and thyroid cancer. Anticancer Research. (4):2531-2534.

28. Khalid AN, Hollenbeak CS, Quraishi SA, Fan CY, Stack BC. (2006) The cost effectiveness of iodine 131 scintigraphy, ultrasonography and fine needle aspiration biopsy in the initial diagnosis of solitary thyroid nodules. Arch Otolaryncol-Head and Neck Surgery. 132(3):244-250.

29. Campenni A, Siracusa M, Ruggeri M, Laudicella R, Pignata SA,Baldari S, Giovanella L. (2017) Differentiating malignant from benign thyroid nodules with indeterminate cytology by ${ }^{99 m}$ Tc- MIBI scan :a new quantitative method for improving diagnostic accuracy. Scientific Reports. 